\title{
TanDEM-X MISSION STATUS: THE NEW TOPOGRAPHY OF THE EARTH TAKES SHAPE
}

\author{
Manfred Zink, Alberto Moreira \\ German Aerospace Center (DLR), Microwaves and Radar Institute \\ Oberpfaffenhofen, Germany, E-Mail: manfred.zink@dlr.de
}

\begin{abstract}
TanDEM-X (TerraSAR-X add-on for Digital Elevation Measurement) opens a new era in spaceborne radar remote sensing [1]-[5]. A single-pass SAR interferometer with adjustable baselines in across- and in along-track directions was formed by adding a second spacecraft (TDX), almost identical to TerraSAR-X (TSX), and flying the two satellites in a closely controlled formation. With typical across-track baselines of 150 to $500 \mathrm{~m}$ a global Digital Elevation Model (DEM) is being generated. To reach this level of DEM quality, all land surfaces have to be mapped at least twice, difficult mountainous terrain requires additional coverage. While data acquisition will be finished by the end of 2014, the processing to the global TanDEM-X DEM is expected to last until the end of 2015. Currently, final DEMs for most of Australia, larger parts of North America, Siberia and South Africa are already available.
\end{abstract}

Index Terms - TanDEM-X, bistatic SAR formation, SAR interferometry, global Digital Elevation Model (DEM)

\section{MISSION OBJECTIVES}

Digital elevation models (DEMs) are of fundamental importance for a wide range of scientific and commercial applications. Within the \pm 60 deg latitude band, data from the Shuttle Radar Topography Mission (SRTM) featuring 6 $10 \mathrm{~m}$ relative height error at $90 \mathrm{~m}$ spatial sampling are currently the primary source of elevation information. Above 60 deg latitude and for Antarctica only lower resolution data are available on a large scale. The primary objective of the TanDEM-X mission is the generation of a world-wide, consistent, up-to-date, and high-precision DEM, featuring $2 \mathrm{~m}$ relative height accuracy at a $12 \mathrm{~m}$ posting [1].

Beyond the generation of a global TanDEM-X DEM as the primary mission goal, local DEMs of even higher accuracy level (posting of $6 \mathrm{~m}$ and relative vertical accuracy of $0.8 \mathrm{~m}$ ) and applications based on Along-Track Interferometry (ATI) like measurements of ocean currents are important secondary mission objectives. ATI also allows for innovative applications to be explored and can be performed by the so-called dual-receive antenna mode on each of the two satellites and/or by adjusting the along-track distance between TSX and TDX to the desired value. Furthermore, TanDEM-X supports the demonstration of new SAR techniques and applications, with focus on multistatic SAR, polarimetric SAR interferometry, digital beamforming and super resolution.

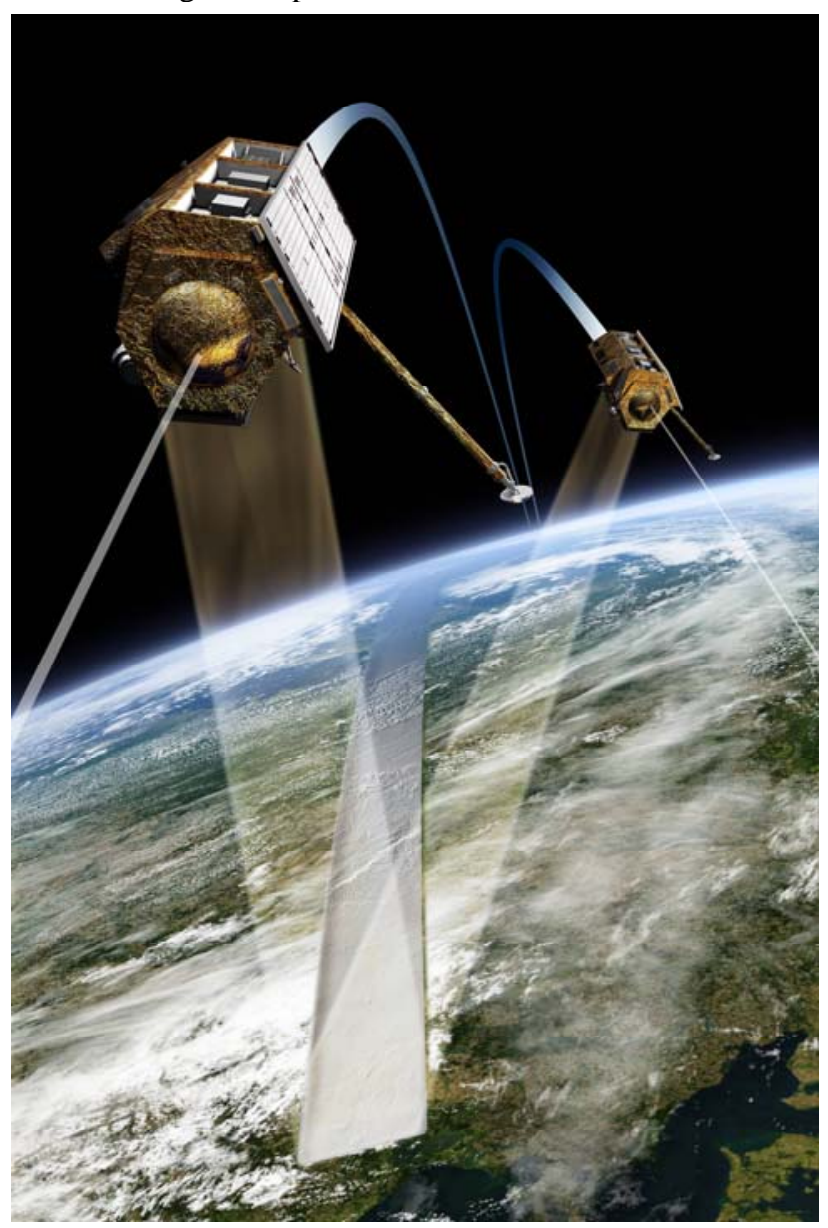

Fig. 1: TSX and TDX satellites flying in close formation. With across-track baseline values ranging from 120 to $500 \mathrm{~m}$ a highresolution global Digital Elevation Model is being generated. 
TanDEM-X has a tight time schedule to reach the main mission goal. The first four years are dedicated to the global DEM acquisitions using baseline geometries optimized for DEM performance. A limited number of scientific acquisitions have already been included during periods with suitable baselines. After completing the acquisitions for the global DEM even larger baselines can be adjusted in a dedicated science phase. This enables higher accuracy DEMs on local scales and the demonstration of new scientific applications.

\section{KEY ELEMENTS OF THE TanDEM-X SYSTEM}

The TDX satellite is a rebuild of TSX with only minor modifications. This offers the possibility for a flexible share of operational functions for both the TerraSAR-X and TanDEM-X missions among the two satellites [6]. The TSX and TDX satellites were designed for a nominal lifetime of 5.5 years. Predictions for TSX based on the current status of system resources indicate up to five extra years (until the end of 2017) of lifetime, providing at least five years of joint operation with TDX.

An orbit configuration based on a Helix geometry has been selected for safe formation flying. The Helix like relative movement of the satellites along the orbit is achieved by combination of an out-of-plane (horizontal) orbital displacement imposed by different ascending nodes with a radial (vertical) separation imposed by the combination of different eccentricities and arguments of perigee. Since the satellite orbits never cross, the satellites can be arbitrarily shifted along their orbits. This enables a safe spacecraft operation without the necessity for autonomous control. Cross- and along-track baselines ranging from $120 \mathrm{~m}$ to $10 \mathrm{~km}$ and from 0 to several $100 \mathrm{~km}$, respectively, can be accurately adjusted depending on the measurement requirement [7].

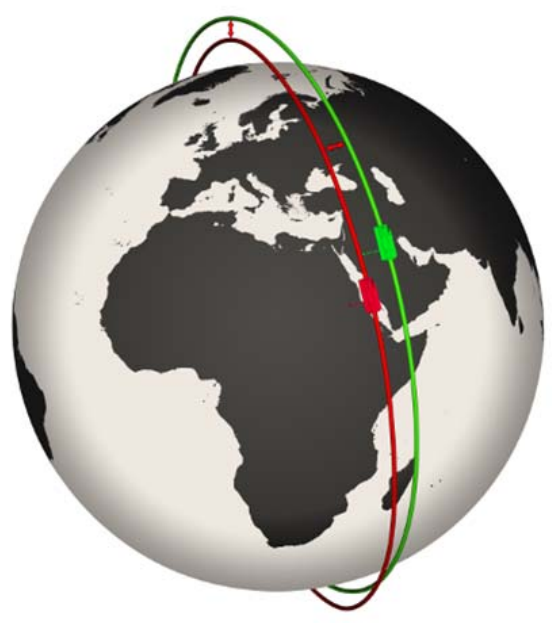

Fig. 2: Orbit illustration of Helix formation.
The missions TerraSAR-X and TanDEM-X jointly share the same space segment consisting of the TSX and TDX satellites and are operated using a common ground segment, that was originally developed for TerraSAR-X and that has been extended for the TanDEM-X mission [8], [9]. Specific new developments are:

- The spatial baseline between the TSX and TDX is derived at millimeter accuracies from on-board GPS measurements taken by the two-frequency IGOR GPS receivers.

- A key issue in operating both missions jointly is the different acquisition scenarios: Whereas TerraSAR-X requests are typically single scenes for individual scientific and commercial customers, the global DEM requires a global mapping strategy. This strategy has also to account for the current formation flying geometry.

- The two satellites downlink their data (in total up to 400 TBytes) to a global network of ground stations: Kiruna in Sweden, Inuvik in Canada, and O'Higgins in Antarctica. After a brief quality check, the data are recorded on tape and shipped to DLR Oberpfaffenhofen for processing and archiving.

- The entire processing chain is a new TanDEM-X specific development. Major design drivers result from the acquisition strategy which requires the combination of several (global) coverages and application of multibaseline processing techniques based on supporting intermediate products [10]. Absolute height calibration relies on a selected set of reference points of the globally distributed elevation data provided by the laser altimeter from NASA's ICESat mission [11].

\section{MISSION STATUS AND OUTLOOK}

Global DEM acquisitions have started in December 2010 and the first and second global coverage (except Antarctica) was completed in March 2012 and March 2013, respectively. After an acquisition period for gap filling, Antarctica was mapped during local winter conditions (in order to achieve a better signal-to-noise ratio) and since early August 2013 the Helix formation has been re-adjusted to allow imaging of difficult mountainous terrain from the opposite viewing geometry [12]. After reversing the Helix formation in April 2014, a subsequent second coverage of Antarctica, and some further gap filling, it is anticipated to finalize data acquisitions for the global DEM in the second half of 2014.

Parallel to the first months of operational data acquisition the team concentrated its efforts on the calibration of the bistatic interferometer. Correction of differential delays between TSX and TDX was necessary to facilitate the utilization of radargrammetry for resolving the ambiguity band. In the meantime, phase, delay and baseline calibration [13] have reached such an accuracy level, that more than $90 \%$ of all so-called Raw DEMs are within 


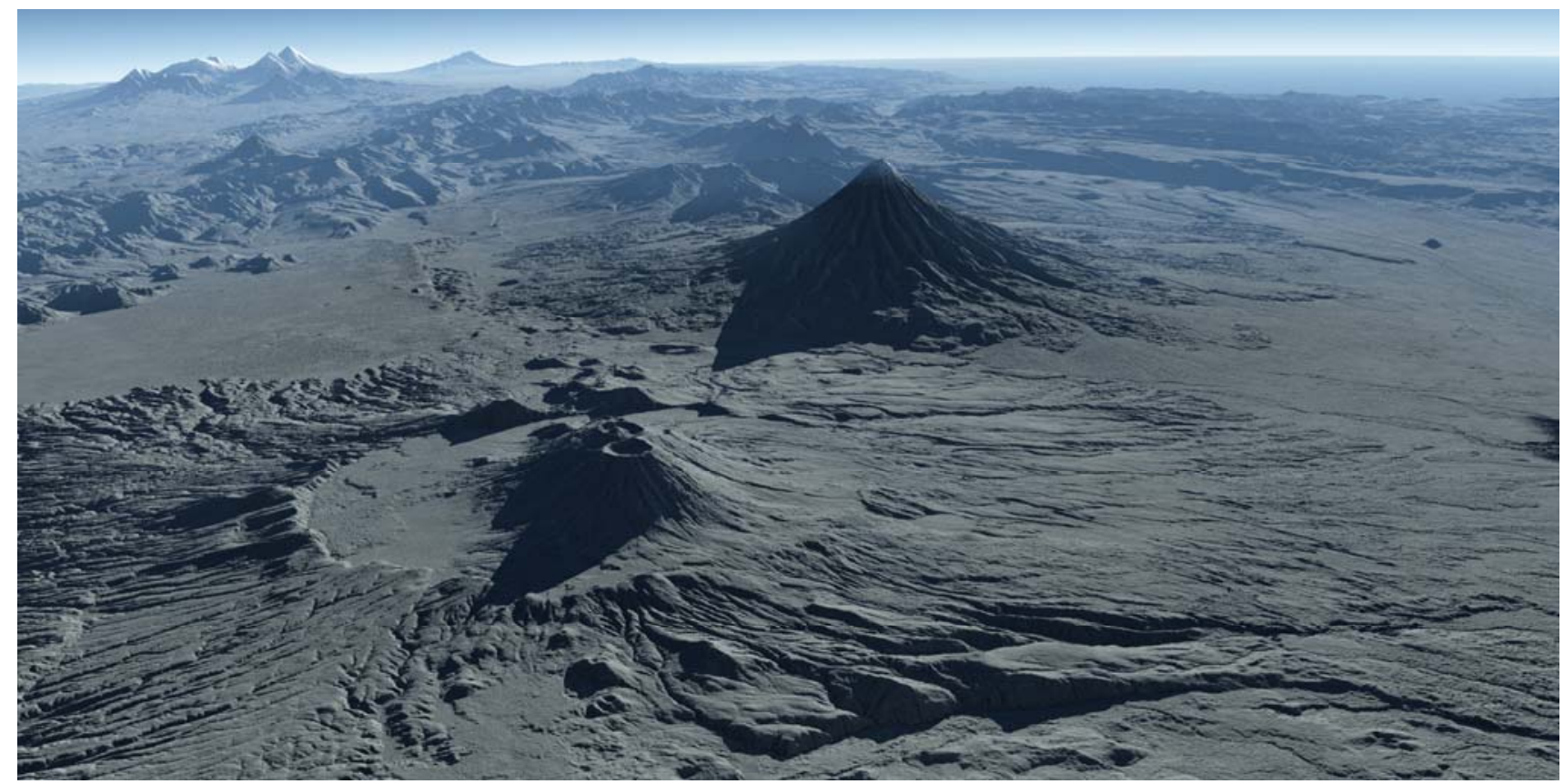

Fig. 3: Perspective view of the Krascheninnikov Caldera (in the front) and the $3528 \mathrm{~m}$ high Kronotsky volcano, rising up as an almost perfect cone. At the horizon on the left one can recognize the Kljutschevskoi volcano, with $4835 \mathrm{~m}$ the highest peak in Kamchatka; early result for processing of mountainous terrain requiring acquisitions from opposite viewing geometries.

\pm 10 m of the DEM derived from SRTM/ICESat data already before the final calibration step using ICESat data as reference heights. More than 400,000 Raw DEMs are generated in a fully automated process employing multibaseline interferometric techniques.

Currently, all efforts are concentrated on the generation of final DEM products for areas requiring only first and second acquisitions. Most of Australia and the rather flat areas of North America, Russia and South Africa have been finished, areas in South America are next in the DEM production. Meanwhile first test runs for difficult mountainous terrain are being performed as well. Fig. 3 shows an area on the Kamchatka peninsula in north-eastern Russia. The so-called land of ice and fire is characterized by the most outstanding volcanic activities with a high density of volcanoes. First examples for final DEMs over mountainous terrain will become available after the summer. It is expected to complete the global DEM by the end of 2015. In total around 16,000 TanDEM-X DEM tiles will be generated. Note here that in the higher latitues one TanDEM-X tile covers up to four $1^{\circ} \mathrm{x} 1^{\circ}$ geocells [14].

A comprehensive system has been established for continuous performance monitoring and verification [15], [16], [17] including feedback to the TanDEM-X acquisition planning for additional acquisitions. Fig. 4 shows as an example the comparison of the TanDEM-X heights against ICESat validation (the majority of ICESat points not being used for DEM calibration). Only a small fraction of the tiles at water borders and over vegetated areas shows a lower accuracy. For the overall region of Australia, the relative height accuracy specification is achieved at a confidence level of $98 \%$.

Beyond the generation of a global TanDEM-X DEM as the primary mission goal, a dedicated science phase is planned to demonstrate the generation of even more

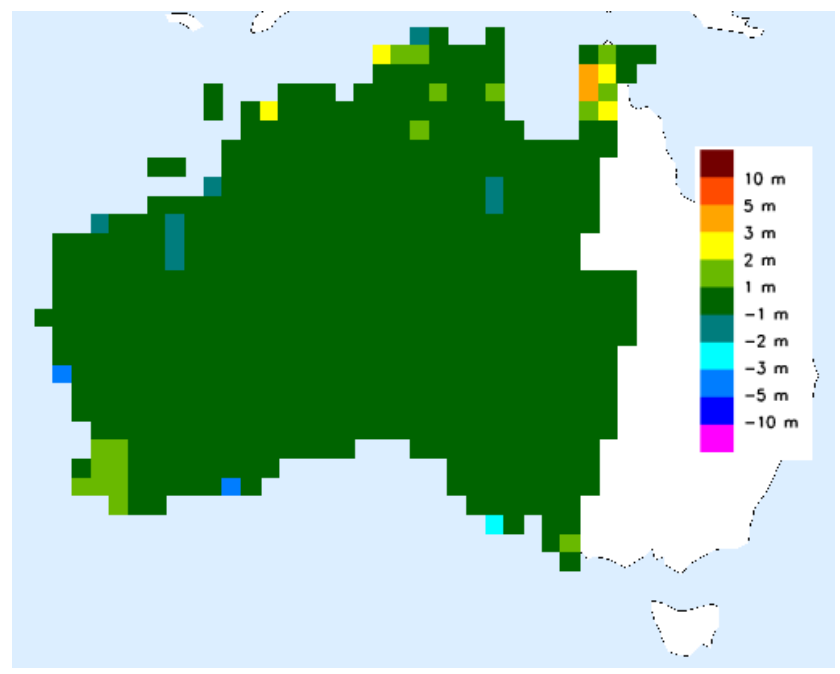

Fig. 4: Absolute height comparison against ICESat points for final TanDEM-X DEMs over Australia. 
accurate DEMs on local scales and applications based on Along-Track Interferometry and new SAR techniques, with focus on multistatic SAR, polarimetric SAR interferometry, digital beamforming and super resolution [18].

\section{CONCLUSION}

For TanDEM-X key technologies like close formation flying, bistatic SAR operation and synchronization, precise baseline estimation and calibration as well as sophisticated bistatic and interferometric processing chains have been implemented. Appropriate safety mechanisms enable safe operation at typical satellite distances between $120 \mathrm{~m}$ and $500 \mathrm{~m}$. The complete mission is fully operational since December 2010 and both satellites as well as the ground system perform remarkably well. Data acquisition for the global DEM will finish in the second half of 2014. The current focus is on the processing of the global DEM data. More than $20 \%$ of the global land mass are already available as final DEM products. The global DEM will be available by the end of 2015, and is expected to become a new reference for commercial and scientific applications since its $3 \mathrm{D}$ information content is at least 30 times more accurate than the presently available global scale DEM data set.

After completion of the DEM data acquisition various scientific radar experiments will be conducted in a dedicated Science Phase (planned from October 2014 until the end of 2015) to demonstrate the great potential of future formation flying interferometric SAR missions to serve novel remote sensing applications.

TanDEM-X has demonstrated the feasibility of an interferometric radar mission with close formation flight and delivers an important contribution for the concept and design of future SAR missions. One example is Tandem-L, a mission proposal for monitoring dynamic processes on the Earth surface with unprecedented accuracy [5], [19].

\section{REFERENCES}

[1] Krieger, G., Moreira, A., Fiedler, H., Hajnsek, I., Werner, M., Younis, M., Zink, M.: TanDEM-X: A Satellite Formation for High Resolution SAR Interferometry. IEEE Transactions on Geoscience and Remote Sensing, vol. 45, no. 11, pp. 3317-3341, Nov. 2007.

[2] Moreira, A., Krieger, G., Hajnsek, I., Hounam, D., Werner, M., Riegger, S., Settelmeyer, E.: TanDEM-X: a TerraSAR-X addon Satellite for Single-Pass SAR Interferometry, Proceedings of the International Geoscience and Remote Sensing Symposium IGARSS, Anchorage, Alaska, 2004.

[3] Zink, M., Bachmann, M., Bräutigam, B., Fritz, T., Hajnsek, I., Krieger, G., Moreira, A., Wessel, B.,: TanDEM-X: The New Global DEM Takes Shape. IEEE-GRSS Magazine, Vol. 2, No. 2, June 2014.

[4] Krieger, G. et al.: TanDEM-X. In: Distributed Space Missions for Earth System Monitoring, Chapter 13, Springer 2012, pp. $387-435$.

[5] Krieger, G., Hajnsek, I., Papathanassiou, K., Younis, M., Moreira, A.: Interferometric Synthetic Aperture Radar (SAR)
Missions Employing Formation Flying. Proceedings of the IEEE, vol. 98, no. 5, 2010.

[6] Pitz, W., Miller, D.: The TerraSAR-X Satellite. IEEE Transactions on Geoscience and Remote Sensing, vol. 48, no. 2, pp. 615-622, Feb. 2010.

[7] R. Kahle, B. Schlepp, S. Aida, M. Kirschner, M. Wermuth, "Flight Dynamics Operations of the TanDEM-X Formation", SpaceOps 2012, Stockholm, Schweden, June 2012.

[8] Buckreuss, S., Schättler, B., The TerraSAR-X Ground Segment, IEEE Transactions on Geoscience and Remote Sensing, vol. 48, no. 2, pp. 623-632, 2010.

[9] Schättler, B., Kahle, R., Metzig, R., Steinbrecher, U., The Joint TerraSAR-X/TanDEM-X Ground Segment, Proc. IGARSS 2011, pp. 2298 - 2301, IEEE, 24.-29. Jul 2011, Vancouver, Canada.

[10] T. Fritz, H. Breit, C. Rossi, U. Balss, M. Lachaise, U. Duque, "Interferometric Processing and Products of the TanDEM-X Mission,” International Geoscience and Remote Sensing Symposium (IGARSS), Munich, Germany, 2012.

[11] B. Wessel, et.al.,"Design of the DEM Mosaicking and Calibration Processor for TanDEM-X.”, European Conference on Synthetic Aperture Radar (EUSAR), Friedrichshafen, Germany, 2008.

[12] D. Borla Tridon, et.al., "TanDEM-X: DEM Acquisition in the Third Year Era”, Int. Journal of Space Science and Engineering, Vol. 1, No.4 pp. 367 - 381, 2013.

[13] J. Hueso González, J. Walter Antony, M. Bachmann, G. Krieger, M. Zink, D. Schrank, M. Schwerdt, "Bistatic System and Baseline Calibration in TanDEM-X to Ensure the Global Digital Elevation Model Quality,” ISPRS Journal of Photogrammetry and Remote Sensing, Vol. 73, pp. 3-11, 2012.

[14] B. Wessel, "TanDEM-X Ground Segment - DEM Products Specification Document”, Public Document TD-GS-PS-0021, Issue 3.0, 2013.

[15] M. Martone, B. Bräutigam, P. Rizzoli, C. Gonzalez, M. Bachmann, G. Krieger, "Coherence Evaluation of TanDEM-X Interferometric Data," ISPRS Journal of Photogrammetry and Remote Sensing, Vol. 73, pp. 21-29, 2012.

[16] P. Rizzoli, B. Bräutigam, T. Kraus, M. Martone, G. Krieger, "Relative Height Error Analysis of TanDEM-X Elevation Data," ISPRS Journal of Photogrammetry and Remote Sensing, Vol. 73, pp. 30-38, 2012.

[17] B. Bräutigam, P. Rizzoli, M. Martone, M. Bachmann, T. Kraus, G. Krieger, "InSAR and DEM Quality Monitoring of TanDEM-X,“ International Geoscience and Remote Sensing Symposium (IGARSS), Munich, Germany, 2012.

[18] Hajnsek, I., Busche, T., Announcement of Opportunity: TanDEM-X Science Phase, TD-PD-PL-0032, 19-May-2014, available at: https://tandemX-science.dlr.de/

[19] Moreira, A. Hajnsek, I., Krieger, G., Papathanassiou, K., Eineder, M., De Zan, F., Younis, M., Werner, M.; Tandem-L: Monitoring the Earth's Dynamics with InSAR and Pol-InSAR. Proceedings of the PolInSAR Workshop, Frascati, Italy, 2009. 